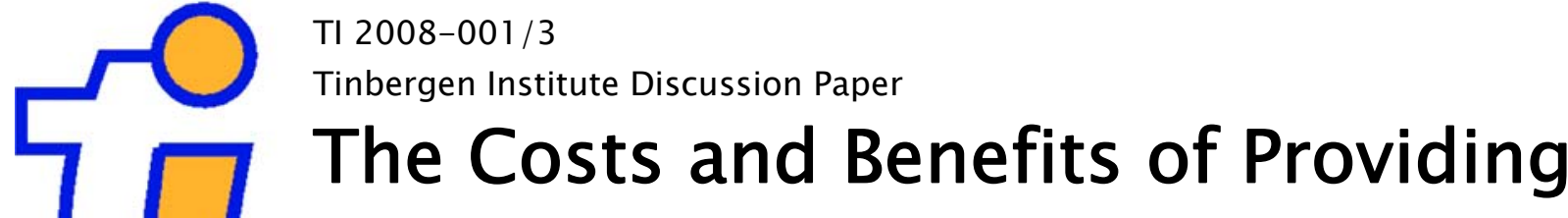 Open Space in Cities
}

Jan Rouwendall,2

J. Willemijn van der Straaten ${ }^{1,3}$

IVU University Amsterdam;

2 Tinbergen Institute;

${ }^{3}$ CPB Netherlands Bureau for Economic Policy Analysis, The Hague. 


\section{Tinbergen Institute}

The Tinbergen Institute is the institute for economic research of the Erasmus Universiteit Rotterdam, Universiteit van Amsterdam, and Vrije Universiteit Amsterdam.

Tinbergen Institute Amsterdam

Roetersstraat 31

1018 WB Amsterdam

The Netherlands

Tel.: $\quad+31(0) 205513500$

Fax: $\quad+31(0) 205513555$

Tinbergen Institute Rotterdam

Burg. Oudlaan 50

3062 PA Rotterdam

The Netherlands

Tel.: $\quad+31(0) 104088900$

Fax: $\quad+31(0) 104089031$

Most TI discussion papers can be downloaded at http:/ /www.tinbergen.nl. 


\title{
The costs and benefits of
}

\section{providing open space in cities}

\author{
Jan Rouwendal (VU) \\ Department of Spatial Economics, VU University, Amsterdam \\ and \\ J. Willemijn van der Straaten (CPB/VU) \\ Department of Spatial Economics, VU University, Amsterdam \\ Netherlands Bureau for Economic Policy Analysis, The Hague
}

\begin{abstract}
Although many researchers have investigated the value of open space in cities, few of them have compared them to the costs of providing this amenity. In this paper, we use the monocentric model of a city to derive a simple cost-benefit rule for the optimal provision of open space. The rule is essentially the Samuelson-condition for the optimal provision of a public good, with the price of land as the appropriate indicator for its cost. The condition is made operational by computing the willingness to pay for public and private space on the basis of empirical hedonic price functions for three Dutch cities. The conclusions with respect to the optimal provision of open space differ between the three cities. Further investigation reveals that willingness to pay for parks and public gardens increases with income, although not as fast as that for private residential space.
\end{abstract}

Key words: spatial planning, provision of public goods, cost-benefit analysis

JEL code: R52, H41, D61

The authors would like to thank Paul Cheshire, Carel Eijgenraam, Martin Koning, Piet Rietveld and Wouter Vermeulen for very useful comments and Jelte Haagsma for research assistance. The authors would also like to thank the Dutch Association of Real Estate Agents (NVM) for using their data. 



\section{$1 \quad$ Introduction}

It is generally recognized that market failures and external effects abound in urban economics (see, for instance, Anas, Arnott and Small, 1998), but it is often not completely clear how effective various possible measures are in improving resource allocation. A specific example is the evaluation of spatial planning policy, which is an almost universally an important part of urban policy. Although economists have paid attention to various aspects of spatial planning (see, for instance, Fischel (1985) on zoning) much remains to be learned.

This paper focuses on one aspect of spatial planning within cities: the provision of open space in the form of parks and public gardens. These are generally considered to be important amenities and many studies have confirmed their significance for the well being of urban residents, usually on the basis of hedonic price studies. A glance at the literature suggests that most studies stop after having established that statistically significant benefits are present. However, for a complete cost-benefit analysis we also need to assess the costs of these amenities. In this paper we make an attempt to introduce the cost side into the analysis by deriving a cost-benefit rule that can be made operational by means of hedonic analysis. We apply this result to the provision of open space in three large cities of the Netherlands.

In the densely populated Netherlands, spatial planning imposes tight restrictions on land use throughout the country, but especially on the western part, which is the economic centre. Probably the best known feature of Dutch physical planning is the prolonged attempt to preserve the polder landscape in the so-called Green Heart of the country's economic core region, the Randstad. As a consequence, the cities in that part of the country are more compact than they would otherwise probably have been. Restrictive spatial planning tends to increase the price for available residential land and this suppresses demand for space. Moreover, lot sizes are determined by local governments who experience severe limitations in designing land for new residential construction. This puts pressure on plans to devote substantial amounts of land to parks and public gardens and may also cause available lot sizes to be even smaller than demand at the prevailing land prices would suggest. It is a priori unclear what this situation implies for the valuation of open space within cities. The pressure on the supply of private land may increase the willingness to pay for this commodity relative to open space. It is, however, also conceivable that parks and public gardens function - to some extent - as a substitute for the consumption of private land, which would suggest that the willingness to pay for this amenity increases as a consequence of the overall scarcity of residential land.

Recently, there has been some debate in the Netherlands about the appropriateness of the currently provided amounts of open space in urban areas. A recent white paper, the 'Nota Ruimte' (VROM, 2006) states that at least $75 \mathrm{~m}^{2}$ of green space should be available within 500 meter of each dwelling. This number is motivated by the importance of green space for 
recreational purposes ${ }^{1}$. In reality, usually less green space is available in the urban areas of the Netherlands. Of the 30 largest cities in the Netherlands, Dordrecht appears to be the only one in the Randstad that satisfies the target of the white paper (Bezemer and Visschedijk, 2003). Even though it is unclear on which evidence the normative figures in the Nota Ruimte has been based, it has been argued in reaction to the white paper that a $500 \mathrm{~m}$ distance is hard to overcome by many elderly people and children, and that $300 \mathrm{~m}$ would be more appropriate (Raad voor het Landelijk Gebied, 2005). In the absence of a cost-benefit analysis of the provision of open space within cities, the significance of such statements is, of course, hard to judge.

Questions concerning the appropriateness of the provision of open space are not specific to the Dutch context. They arise in every city. There exists an international literature on the value of open space, which has recently been reviewed in McConnell and Walls (2005). This paper concentrates on the provision of open space within cities. Even though we recognize (as will be clear from the previous paragraphs) that this may have a relationship with the preservation of open space surrounding cities, open space within cities will be dealt here as an important subject in its own right.

Our analysis of open space within cities is relatively close to that presented in Cheshire and Sheppard's (2002) as an element of their welfare economic analysis of the broader concept of land use planning. We follow them in their adoption of the monocentric model as a useful framework for the analysis and in their use of the hedonic price function as the main tool for making the theory operational.

This paper is organized as follows. In the next section, we provide a theoretical analysis of the provision of open space as a neighbourhood-specific public good in the context of the monocentric model. Section 3 presents our estimates of a hedonic price function for the three largest Dutch cities. Section 4 is devoted to a further analysis of the demand for open space and residential land. Section 5 concludes.

${ }^{1}$ VROM (2006), p 88. 


\section{A framework for cost-benefit analysis}

In this section, we develop a model for a monocentric city in which a benevolent planner provides open space by means of spatial planning policy. The model is outlined in 2.1 and the policy evaluation question is considered in 2.2. Section 2.3 discusses the suggested cost-benefit rule and its operationalization and applicability in real world circumstances.

\section{$2.1 \quad$ The model}

We consider the demand for open space in a monocentric city, which is the workhorse of urban economic analysis (see, for instance, Fujita, 1989, for an exposition of the model). The variant of the model we use has a homogeneous population of households who derive utility $u$ from the consumption of residential land $h$, a composite consumption good $c$ and open space $S$. We assume that all households living close by have free access to this open space and will therefore treat it as a local public good. To do so, we view the city as consisting of a number of neighbourhoods, indexed by $i$ and we ignore differences in the distance to the city centre between different locations in the same neighbourhood. The available open space within a neighbourhood contributes to the utility of all inhabitants, but not to the inhabitants of other neighbourhoods. A household takes the available amount of open space in the neighbourhoods as given.

The utility function of the household is:

$u=u\left(h_{i}, c_{i}, S_{i}\right)$

and the budget restriction:

$y=p_{i} h_{i}+c_{i}+t x_{i}$

with $y$ denoting household income, $p_{i}$ the price of land in neighbourhood $i, t$ the commuting cost per unit $\mathrm{t}$ of distance, and $x_{i}$ the distance between neighbourhood $i$ and the city centre. We have normalized the price of the composite good to 1 . Households maximize their utility by choosing a neighbourhood $i$ and thereby determining their optimal consumption of housing and the composite good. The price for land in the neighbourhoods adjusts in such a way that in every neighbourhood the same level of utility is reached.

It is well known that the equilibrium rent level in the city can be described by a bid rent function. A bid rent function gives the maximum amount of money a household is willing to pay for one unit of land when it has to reach utility level $u^{*}$ and income, unit commuting cost and the available amount of open space are given. Formally, the bid rent function $\psi$ is defined for each neighbourhood $i$ as: 
$\psi\left(x_{i}, u^{*}, y, t, S_{i}\right)=\max _{h}\left(\frac{y-t x_{i}-C\left(u^{*}, h_{i}, S_{i}\right)}{h_{i}}\right)$

where $C($.$) denotes the amount of the composite good that a household must consume in order$ to reach utility $u^{*}$ conditional on housing consumption $h_{i}$ and open space $S_{i}{ }^{2}$. The first order condition of the maximization in (2.3) implies:

$\psi\left(x_{i}, u^{*}, y, t, S_{i}\right)=-\frac{\partial C\left(u^{*}, h_{i}, S_{i}\right)}{\partial h_{i}}$.

This equation states that the value of the bid rent function equals the household's marginal willingness to pay for land. In a market equilibrium all households have the same gross income and reach the same utility level and are therefore on the same bid rent curve. The value of this bid rent curve is then equal to the price of land $p_{i}$.

\subsection{Optimal provision of open space}

The amount of land available for residential purposes $\left(R_{i}\right)$ and parks or public gardens $\left(S_{i}\right)$ in neighbourhood $i$ is $L_{i}$. For simplicity we take this amount to be equal in all neighbourhoods.

(At the end of the next section we will relax this assumption.)

To study the optimal provision of open space in the city, we introduce a planner who maximizes the value of the social surplus generated by the city. This surplus is defined as the difference between the total amount of income earned in the city and the costs that have to be made to enable its inhabitants to reach a given utility level $u^{*}$.

The social planner chooses $h_{i}, R_{i}$ and $S_{i}$ such that the value of the social surplus of each neighbourhood $\mathrm{i}\left(S S_{i}\right)$ is maximized, while taking into account the constraint:

$R_{i}+S_{i}=L_{i}$

The social surplus $S S$ of the city is the sum of the social surpluses of all neighbourhoods:

$S S=\sum_{i} S S_{i}=\sum_{i}\left[\frac{R_{i}}{h_{i}}\left[y-t x_{i}-C\left(u^{*}, h_{i}, S_{i}\right)\right]-\left(R_{i}+S_{i}\right) p^{a g r}\right]$

\footnotetext{
${ }^{2}$ The value of $\mathrm{C}(\cdot)$ is found by 'inverting' the equation $u^{*}=u(c, h, S)$ with respect to $c$. It is not difficult to verify that
} $\partial C / \partial h$ is equal to $(\partial u / \partial h) /(\partial u / \partial c)$. 
with $p^{a g r}$ is the price of agricultural land.

First order conditions are:

$-\frac{\partial C}{\partial h_{i}}=\frac{y-t x_{i}-C\left(u^{*}, h_{i}, S_{i}\right)}{h_{i}}$

$\frac{y-t x_{i}-C\left(u^{*}, h_{i}, S_{i}\right)}{h_{i}}=p^{a g r}+\mu_{i}$

$\frac{R_{i}}{h_{i}}\left(-\frac{\partial C}{\partial S_{i}}\right)=p^{a g r}+\mu_{i}$.

In these equations $\mu_{i}$ is the Lagrange multiplier associated with constraint (2.6). We can easily remove it by combining the last two conditions as:

$\frac{R_{i}}{h_{i}}\left(-\frac{\partial C}{\partial S_{i}}\right)=\frac{y-t x_{i}-C\left(u^{*}, h_{i}, S_{i}\right)}{h_{i}}$.

Equation (2.10) is a Samuelsonian condition for the optimal provision of a public good. The number of households in neighbourhood $i$ equals $R_{i} / h_{i}$ and the left-hand-side therefore gives the total marginal willingness to pay for open space by all households. The right hand side is the opportunity cost for providing open space, which, by (2.7), equals the willingness to pay for residential land. In the context of a market economy this willingness to pay is equal to the market price $p_{i}$ for residential land in neighbourhood $i$.

We assume that a neighbourhood will be developed whenever it contributes to the total surplus of the city, that is, whenever the value of the land in residential use (the provision of the appropriate amount of open space included) exceeds its value in agricultural use. This is similar to the way the boundary of the city is determined in monocentric models where no neighbourhoods are distinguished.

\subsection{A cost-benefit rule}

The derivations of the previous subsection suggest a relatively straightforward cost-benefit rule for the provision of open space. Open space should be provided until the sum of the marginal willingness to pay of all the inhabitants of a neighbourhood is equal to the market value of residential land in the neighbourhood: 
$\frac{R_{i}}{h_{i}}\left(-\frac{\partial C}{\partial S_{i}}\right)=p_{i}$

It should, of course, immediately be noted that neither the willingness to pay for open space nor the market value of residential land is directly observable. Open space is a public good for which no market price exists and urban residential land is in practice almost always traded jointly with the houses constructed on it. Fortunately, both problems can be solved by the hedonic method.

To see this, observe that in a market equilibrium every household must reach the equilibrium utility level $u^{*}$. This requires that a hedonic price function $P(h, S, x)$ emerges that facilitates such an equilibrium. The budget restriction of a household can then be written as $y-t x=c+P(h, S, x)$, and we can substitute it in the utility function to write the condition for a market equilibrium as:

$u(y-t x-P(h, S, x), h, S)=u^{*}$.

Even though this hedonic price function is only defined in our model for a finite number of neighbourhoods, we may reasonably conjecture that a smooth function exists that takes on the same values as the actual hedonic function for all neighbourhoods and is also defined for other possible combinations of $h, S$, and $x$. Since small changes in $h, S$ and $x$ should not change utility, this more general smooth hedonic price function must have:

$$
\begin{aligned}
& \frac{\partial u}{\partial C}\left(-\frac{\partial P}{\partial h}\right)+\frac{\partial u}{\partial h}=0, \\
& \frac{\partial u}{\partial C}\left(-\frac{\partial P}{\partial S}\right)+\frac{\partial u}{\partial S}=0 \\
& \frac{\partial u}{\partial C}\left(-t-\frac{\partial P}{\partial x}\right)=0
\end{aligned}
$$

It follows immediately from (2.13) that the partial derivative of the hedonic price function with respect to $h$ is the marginal willingness to pay for residential land, and from (2.14) that the partial derivative of the hedonic price function with respect to $S$ is the marginal willingness to pay for open space. Equation (2.15) shows the familiar property that the house price should contain a compensation for commuting cost. ${ }^{3}$

\footnotetext{
${ }^{3}$ In a market equilibrium, the price for land $P(x)$ that we used above, should be interpreted as the partial derivative of the hedonic price function, $\partial P / \partial h$, evaluated at $\mathrm{x}$ and at the given amount of open space $\mathrm{S}(\mathrm{x})$.
} 
The version of the cost-benefit rule (2.11) that will be used in our empirical work is therefore:

$N_{i}\left(-\frac{\partial C}{\partial S_{i}}\right)=\left(-\frac{\partial C}{\partial h_{i}}\right)$,

where $N_{i}$ denotes the number of households in neighbourhood $i$ and the willingness to pay for open space and for residential land are computed by means of a hedonic price function.

Even though we derived (2.16) in the context of a simple monocentric model that incorporates a number of assumptions whose empirical relevance can be questioned, it is useful to note that it is robust to relaxation of a number of these assumptions. For instance, if lot size or housing consumption $h$ is fixed or predetermined (by history and high adjustment costs) there will still emerge a hedonic price function that establishes the equilibrium (2.12) and equations (2.13)-(2.15) will be valid. Moreover, a housing market equilibrium as implied by (2.12) will also emerge if there is an urban growth boundary, which causes land prices at the boundary of the city to exceed the value of agricultural land. These observations are of particular importance for the situation in the Netherlands where, as we noted in the introduction, restrictive spatial planning may well have resulted in house prices that are higher and lot sizes that are smaller than market forces would suggest. Even in these circumstances, a social planner should provide open space until condition (2.16) is satisfied.

If the city is populated by groups that differ in their preferences for residential land and parks and public gardens, condition (2.12) must be valid for the set of neighbourhoods in which members of the same group reside and eqs. (2.13)-(2.15) also follow. In such circumstances the provision of open space per neighbourhood should be adjusted to the tastes of its inhabitants and condition (2.16) remains valid. As we will see below, our data suggest that there is considerable heterogeneity among urban households.

To check for the appropriate provision of open space, one should compute the partial derivatives of the hedonic price function and use them to see if equation (2.16) is satisfied. This is the essence of the empirical analysis that follows. 


\section{Estimation of hedonic price functions}

We start this section with a brief review of existing literature and some further remarks on the

Dutch context. Then we introduce the data that we use for estimating the hedonic price functions and present the results.

\section{1 $\quad$ Existing literature}

The value of open space has been studied intensively over the past decades. For instance, an early study by Brown and Pollakowski (1977) finds that publicly accessible open space in lakefront communities in the Seattle area has a positive effect on house prices: the greater the open space around a house, the higher the price, all else equal. House prices decrease with distance from the lakefront and are lower if a house does not have a lake view. Many other studies have been published since then, and McConnell and Walls (2005) provides a useful survey of this still growing literature. Even though in recent years interest in stated preference analyses for the valuation of open space has increased, the standard approach still appears to be the elaboration of a hedonic price function for housing.

The fundamental observation underlying the hedonic method is that the value of open space is revealed in the prices of houses in its vicinity, as shown in equation (2.14) above. If people attach value to the proximity of open space, they also attach a higher value to a house that provides this amenity. They are therefore willing to bid more for such a house. Rosen's (1974) original analysis concerned a market with perfect competition, but the suggested methodology for investigating consumer demand is equally applicable under alternative market conditions (see e.g. Bajari and Benkard, 2005).

Since a recent survey of the international literature on the valuation of open space is available, we will only briefly discuss a few studies for the Netherlands, to which our empirical work refers. Luttik (2000) studied a limited number of relatively small areas and found that a view on open space increases the value of a house with 6 to 12 percent. However, she reported that it was much more difficult to demonstrate any effect of a park or a recreational area bordering the residential area. For only two of the eight areas she examined significant coefficients for these variables were found. Visser and van Dam (2005) analyzed the housing market in the Netherlands as a whole and focused on the contribution of environmental and neighbourhood characteristics to house price differences. These authors report positive and significant effects of the presence of a park within 50 meters, and of the percentage of land considered as parks in the neighbourhood. These Dutch studies therefore suggest that effects of open space on house prices operate especially on a small spatial scale, which confirms findings of the international literature. For instance, Orford (1999) reports that a distance of a few blocks decreases the effect of living close to a major park in Cardiff (Wales) on the property values by 50 percent. This suggests that the effect of open space on house values may become negligible 
for distances well below the $500 \mathrm{~m}$ used in the Dutch white paper mentioned in the introduction.

\subsection{The Dutch context}

Traditionally, the Netherlands has a large share of public housing. Especially in the large cities the share of the rental sector is substantial. Rents are controlled, and their values are determined by a system of points that takes little account of neighbourhood amenities. For this reason it makes no sense to carry out a hedonic price analysis on rental housing. Hence, we focus on the owner-occupied sector. Currently the large Dutch cities, where the rental sector is overrepresented, are putting much emphasis on their attractiveness for higher income households which tended to move to suburban regions. They do so by constructing more luxury housing, and also by paying more attention to urban amenities, open space being an important example.

The majority of the transactions on the housing market concern existing houses and here it is evident that floor area and most of the housing characteristics have to be taken as given by a buyer, as well as the presence of parks and gardens. Our data refer to Amsterdam, The Hague and Rotterdam. Since the housing stock and the provision of open space in these three cities differ for historical reasons we expect the hedonic price functions for these cities to be different. For instance, the $17^{\text {th }}$ century inner city of Rotterdam was destroyed in the Second World War, whereas many elements of the inner city of Amsterdam still date from that period. Moreover, Amsterdam and Rotterdam experienced very fast growth in the $19^{\text {th }}$ century due to rapid industrialization, whereas the growth of The Hague was more gradual and related to its status as the residence of the national government.

As we noted in the previous section, the constraints resulting from such differences in the historical development of the housing stock do not prevent the emergence of a market equilibrium in which marginal prices correctly reveal the marginal willingness to pay for these characteristics and amenities.

\subsection{Data}

The data we use are provided by the Dutch Association of Real Estate Agents (NVM) and concern housing transactions in the year 2000. All houses sold by NVM-real-estate agents ${ }^{4}$ in the three major Dutch cities Amsterdam, The Hague and Rotterdam ${ }^{5}$ in that year are included in

\footnotetext{
${ }^{4}$ Of all the houses sold in the Netherlands, 65-70 percent are sold by NVM real estate agents.

${ }^{5}$ Municipalities that are adjacent to Amsterdam, The Hague or Rotterdam are not included in this analysis. Also postal areas in which there are no housing transactions by NVM- brokers in the year 2000, are not included in the analysis. Most of the harbour regions in Rotterdam and Amsterdam are therefore not included in the analysis. We skip Rijnpoort (Hoek van Holland), a part of Rotterdam that is not adjacent to any other area of Rotterdam.
} 
the data base. The variables include the transaction price and numerous structural characteristics, for instance, floor area, volume, number of rooms, and location.

To be able to investigate the effects of land use in the vicinity of the sold houses, we added information about land use. The relevant information was acquired from Statistics Netherlands (CBS) that provided an integrated data set containing information about 38 types of land use on grid cells of 100 by 100 meter. For the purposes of the present paper we used information about five categories of land use:

1. Parks and public gardens

2. Agricultural land

3. Industrial area

4. Service area (shops and public facilities)

5. Open water.

Each of these categories are aggregates of some of the 38 basic types of land use distinguished in this data base. Parks and public gardens are land to which public access is explicitly or implicitly provided: it includes, besides parks and public gardens, also forest and water with a recreational function, for example a yacht-basin. Industrial area includes building land. Service area consists of shops and social and cultural facilities. The last category, called 'open water', indicates canals and the lake IJ in Amsterdam, the North Sea in The Hague and the river Maas in Rotterdam.

\section{Figure 3.1 Percentage parks and public gardens in three Dutch cities}
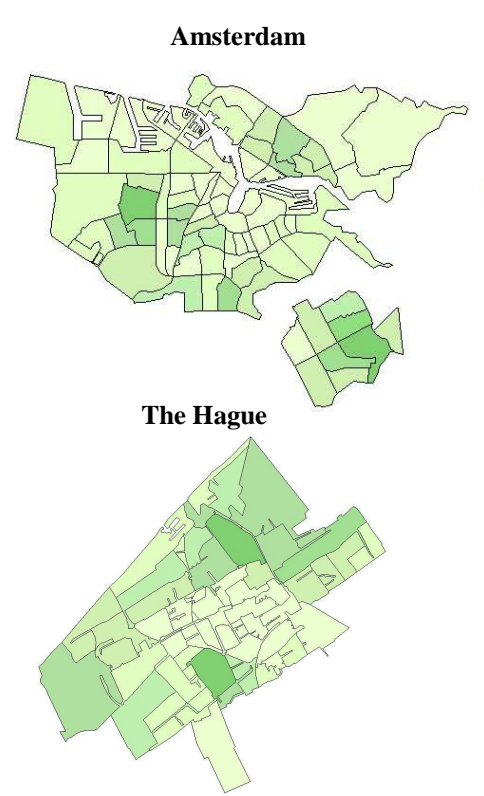

\section{Rotterdam}

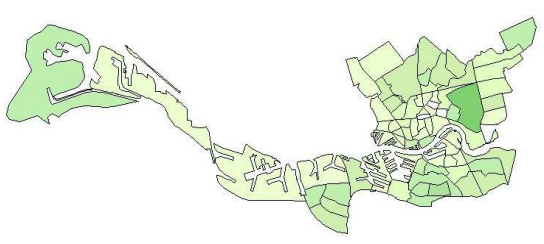

Percentage open space

$\square 0$ to $5 \%$

5 to $10 \%$

10 to $15 \%$

15 to $20 \%$

20 to $25 \%$

25 to $30 \%$

30 to $35 \%$

35 to $100 \%$ 
Figure 3.1 shows the spatial distribution of parks and public gardens over postal code areas in the three cities. It shows that there is a considerable amount of variation in this amenity in each of them. In Amsterdam the highest scores are in some western and south-eastern postal code areas that are generally regarded as problem areas. The best known park in Amsterdam is the Vondelpark, which is located to the southwest of the canal area. The surroundings are generally regarded as a highly attractive residential area. In Rotterdam the highest score is associated with the area surrounding the Kralingse Plas. The Hague has a small forest close to the central station, while there is also a considerable amount of green open space in the dunes and especially in the area between the former fisherman village Scheveningen and the former edge of The Hague. These area, as well the Kralingse Plas are generally regarded as attractive residential locations. In this respect these cities seem to be somewhat different from Amsterdam.

\subsection{Specification and estimation of a hedonic function}

We use three types of explanatory variables: structural variables, amenities and other locational variables. The structural variables include the quantitative variables volume and floor area. Categorical variables indicate the age of the house, the presence of a gas heater (revealing the absence of central heating), a garage, a garden, the number of rooms, the type of house (of which apartment is taken as reference), the maintenance quality of the house (bad maintenance is taken as reference), and the status of a house as a monument.

The second set of explanatory variables concerns the location of the house. We included the distance of the house to the city centre (the location of the central station was taken as the centre), the ethnical composition and the population density of the area in which the house is located. ${ }^{6}$ We have also included neighbourhood dummies. The importance of taking into account these effects in studying the value of open space has recently been stressed by Anderson and West (2006). ${ }^{7}$

Because we know the exact location of the house we were able to obtain information about the amount of amenity variables in the vicinity of the house. Of each grid of 100 by 100 meter in which the house is located, the percentage of land taken by this amenity was computed. That is, for each grid we calculated the percentage of parks and public gardens, agricultural land, industrial area, services area, and amount of water. In our baseline specification we took the average of these percentages over the grids within a distance of 500 meter from the house as the explanatory variables. Other specifications, to be discussed below, measured this amenity at a different spatial level.

\footnotetext{
${ }^{6}$ Note that the variables ethnical composition and population density are included on a much smaller scale than the neighbourhood dummies.

${ }^{7}$ The neighbourhood dummies control for a number of effects that may be hard to observe and/or difficult to measure in other ways. For instance, they should be expected to control for differences in accessibility that are related to the interurban road network.
} 
In the course of the year 2000 Dutch house prices increased considerably. Since our database informs us about the transaction, data we were able to control for changes in the price level by including monthly dummies.

In comparison with other studies our data base is rich. First of all we are able to estimate separate equations for three different cities. Second, we are able to control for unobserved differences in urban areas by neighbourhood dummies. Finally, the locational variables and amenities could be determined for each house separately or at a very detailed spatial level.

We use a spatial error model to deal with spatial autocorrelation ${ }^{8}$. To be able to do so, the distances between all houses in our data base were computed. For distances smaller than 1 kilometre we used the inverse of the distance (expressed in meters) as the relevant weight and we scaled the weighting matrix. Estimation proceeded by the GMM approach of Kelejian and Prucha (1999). We also estimated a spatial lag model. The spatial lag parameters are small and the coefficients for open space and floor area did not change much. Because the welfare interpretation of a spatial lag model is not straightforward (sse, for instance, the discussion in Small and Steimetz, 2007), we do not report the results ${ }^{9}$ and concentrate on the spatial error model.

We removed all observations that referred to a house containing less than $100 \mathrm{~m}^{3}$ and we excluded 0.5 percent of the remaining observations of the highest and lowest values of the transaction price and floor area of each city. One observation, that concerned a house that was located more than $1 \mathrm{~km}$ of all other houses in our data, was also excluded.

Our baseline specification has the logarithm of the transaction price as the dependent variable. Table A in the Appendix gives a brief description of all the variables that we use, table B provides descriptive statistics. The estimation results are presented in Table 3.1.

Structural attributes appear with expected sign and are in general statistically significant in the three equations. Capacity and floor area have a particularly strong effect on the house price. Well-maintained houses - a qualification that is provided by the realtors - sell at significantly higher prices.

The three locational characteristics reported in Table 3.1 all have the expected sign and are statistically significant. Note that we also controlled for neighbourhood characteristics by introducing a series of dummies, although their estimated coefficients are not reported.

\footnotetext{
${ }^{8}$ The coefficients of the explanatory variables estimated by the spatial error model are almost identical to those obtained by the OLS regression, as should be the case under standard assumptions.

${ }^{9}$ The coefficient of the spatial lag is 0.035 for Amsterdam, 0.060 for The Hague and 0.0010 for Rotterdam. The coefficient for parks and public gardens slightly decreases in Amsterdam and The Hague but increases in Rotterdam.

12
} 
Table 3.1 Estimation results of hedonic price functions for three Dutch cities

\begin{tabular}{|c|c|c|c|c|}
\hline & (1a) & (1b) & (2) & (3) \\
\hline & Amsterdam & Amsterdam & The Hague & Rotterdam \\
\hline \multicolumn{5}{|l|}{ Structural characteristics } \\
\hline $\log \left(m^{3}\right)$ & $0.487(0.019)$ & $0.482(0.017)$ & $0.417(0.028)$ & $0.453(0.041)$ \\
\hline Log (floor area) & $0.315(0.017)$ & $0.315(0.022)$ & $0.399(0.025)$ & $0.324(0.036)$ \\
\hline No central heating & $-0.069(0.010)$ & $-0.069(0.010)$ & $-0.078(0.011)$ & $-0.138(0.025)$ \\
\hline Garage & $0.114(0.019)$ & $0.108(0.019)$ & $0.051(0.020)$ & $0.099(0.031)$ \\
\hline Garden & $0.039(0.009)$ & $0.039(0.009)$ & $0.216(0.011)$ & $0.044(0.023)$ \\
\hline Number of rooms & $0.018(0.004)$ & $0.018(0.004)$ & $0.033(0.005)$ & $0.017(0.008)$ \\
\hline Terraced house & $0.085(0.015)$ & $0.092(0.015)$ & $0.093(0.016)$ & $0.061(0.031)$ \\
\hline Detached & $0.153(0.049)$ & $0.166(0.048)$ & $0.239(0.077)$ & $0.133(0.075)$ \\
\hline Semi-detached & $0.042(0.043)$ & $0.048(0.043)$ & $0.006(0.043)$ & $0.090(0.055)$ \\
\hline Monument & $0.044(0.018)$ & $0.047(0.018)$ & $0.238(0.054)$ & $0.126(0.111)$ \\
\hline Maintenance good & $0.119(0.011)$ & $0.118(0.011)$ & $0.126(0.011)$ & $0.125(0.024)$ \\
\hline \multicolumn{5}{|l|}{ Locational variables } \\
\hline Distance to city centre & $-0.090(0.004)$ & $-0.084(0.005)$ & $-0.021(0.005)$ & $-0.048(0.007)$ \\
\hline Percentage ethnic minorities & $-0.006(0.000)$ & $-0.006(0.000)$ & $-0.005(0.001)$ & $-0.002(0.001)$ \\
\hline Population density & $-0.006(0.001)$ & $-0.004(0.000)$ & $-0.007(0.001)$ & $-0.007(0.003)$ \\
\hline \multicolumn{5}{|l|}{ Amenities } \\
\hline Percentage parks, public gardens & $0.002(0.001)$ & $0.000(0.001)$ & $0.009(0.001)$ & $0.006(0.001)$ \\
\hline Percentage Vondelpark & & $0.007(0.001)$ & & \\
\hline Percentage agricultural & $0.001(0.001)$ & $0.001(0.001)$ & $-0.002(0.001)$ & $-0.002(0.001)$ \\
\hline Percentage industrial area & $-0.002(0.001)$ & $-0.001(0.001)$ & $-0.002(0.001)$ & $-0.006(0.001)$ \\
\hline Percentage service area & $0.002(0.001)$ & $0.001(0.001)$ & $0.008(0.001)$ & $0.004(0.001)$ \\
\hline Percentage open water & $-0.002(0.001)$ & $0.000(0.001)$ & $0.005(0.001)$ & $0.005(0.001)$ \\
\hline $\mathrm{R}^{2}$ & 0.89 & 0.89 & 0.90 & 0.87 \\
\hline Autoregressive par. & 0.32 & 0.32 & 0.35 & 0.40 \\
\hline$\sigma^{2}$ & 0.17 & 0.17 & 0.21 & 0.22 \\
\hline $\mathrm{N}$ & 3868 & 3868 & 4417 & 2334 \\
\hline
\end{tabular}

Note: The equations also contained controls for year of construction (before 1905, 1906-30, 1931-44, 1945-59, 1960-70, 1971-1980, 1981-1990), month of sale and for neighbourhoods (14 in Amsterdam, 7 in The Hague, 9 in Rotterdam). Full estimation results are available from the authors upon request. Standard errors are given in parentheses.

The coefficients for parks and public gardens - which are of key interest in the present study are significant and of the expected sign in all three cities. This confirms our expectation that open space has a positive value for urban residents. A household living in $\mathrm{Amsterdam}^{10}$ is on average willing to pay 401 euro for a one percent increase of parks and public gardens in the 500 meter circle around the house. In The Hague the willingness the pay for this amenity is equal to 1455 euro and in Rotterdam 987 euro. The coefficient that has been estimated for Amsterdam in column (1a) is much lower than that for the other two cities. Closer examination of the results suggested that it is caused by heterogeneity in the valuation of parks and public gardens in Amsterdam. In column (1b), we distinguish the effect of the Vondelpark, the best known park of Amsterdam, located close to the centre of the city, from that of all other parks

\footnotetext{
${ }^{10}$ Strictly speaking we should note that our results refer only to households who bought a home in the year 2000.
} 
and public gardens. The results reveal that most of the positive effect of open space in Amsterdam, as shown in column (1a), was caused by the Vondelpark, whereas the effect of other parks and public gardens appears to be negligible. The coefficient for the Vondelpark is of the same order of magnitude as the coefficient for open space for The Hague and Rotterdam, whereas that of the original variable is now very small and insignificant.

As written in section 3.3, the postal areas in Rotterdam and The Hague with a high amount of open space are regarded as attractive residential areas. In Amsterdam however, the postal areas with a high score of open space can be regarded as problem areas, like The Bijlmer and Slotervaart. ${ }^{11}$ A possible explanation is that the valuation of open space depends crucially on the pleasure you experience when visiting it. This pleasure is diminished by a - real or perceived - lack of social safety. This, and related, aspects seem hard to measure objectively, but may well affect the estimation of our hedonic price function. It might explain the fact that the effect of parks and public gardens in Amsterdam, apart from the Vondelpark, is negligible.

The presence of industries in the vicinity of a house decreases its value, the presence of shops and social or cultural activities increases its value. Results for the other two amenities are less clear, however.

We experimented with several alternative specifications. Using the inverse of the squared distance in the spatial weight matrix did not change the results. We have estimated the equations with the percentages open space and other amenities within $100 \mathrm{~m}, 300 \mathrm{~m}, 500 \mathrm{~m}$ and $1000 \mathrm{~m}$ circle around the house as explanatory variables. ${ }^{12}$ The estimated coefficients for the percentage parks and public gardens are reported in Table 3.2.

\begin{tabular}{lrrrr}
\hline Table 3.2 & Coefficients for open space for different specifications of the variable & \\
& $100 \mathrm{~m}$ circle & $300 \mathrm{~m}$ circle & $500 \mathrm{~m}$ circle & $1000 \mathrm{~m}$ circle \\
& & & & \\
(1) Amsterdam & $0.0016(0.0003)$ & $0.0018(0.0004)$ & $0.0017(0.0005)$ & $0.0009(0.0006)$ \\
(1a) Amsterdam & $0.0004(0.0003)$ & $0.0003(0.0004)$ & $0.0001(0.0006)$ & $-0.0009(0.0007)$ \\
$\quad$ Vondelpark & $0.0045(0.0006)$ & $0.0060(0.0007)$ & $0.0073(0.0010)$ & $0.0080(0.0009)$ \\
(2) The Hague & $0.0050(0.0003)$ & $0.0072(0.0004)$ & $0.0089(0.0006)$ & $0.0123(0.0006)$ \\
(3) Rotterdam & $0.0039(0.0005)$ & $0.0052(0.0006)$ & $0.0061(0.0011)$ & $0.0088(0.0008)$ \\
\hline
\end{tabular}

The figures in Table 3.2 show that the estimated coefficients for parks and public gardens increase when we take a larger area around the house to compute them. (Except for (1), Amsterdam, and (1a), Amsterdam outside the Vondelpark area, although these variables are insignificant.) At first sight these results might appear to contradict our conjecture - based on the earlier literature - of a strong distance decay effect. However, it should be realized that a

\footnotetext{
${ }^{11}$ This evokes the question whether the positive Vondelpark effect is in reality a residential area effect. To investigate this issues we added a dummy for the Vondelpark area. This resulted in an insignificant coefficient for the dummy, while that for the Vondelpark hardly changed.

${ }^{12}$ Our data do not allow the make a distinction between houses that have a view on the park, and houses that are located close by a park, but do not have a view on it.
}

14 
given percentage of open space in a larger circle implies a much larger area of open space. For example, the amount of square meter of open space in a circle of 500 meter should be 2,7 times more than the amount of open space in a 300 meter circle, in order to have the same percentage of open space. To calculate the marginal price per $\mathrm{m}^{2}$, we have to divide the coefficient of open space by the corresponding surface area. ${ }^{13}$ The marginal price of open space per $\mathrm{m}^{2}$ is equal to:

$$
\operatorname{MP}_{\text {openspace }}\left(\mathrm{m}^{2}\right)=\frac{100 * \text { coefficient }}{\text { openspace }} * P_{\text {pricehouse }}
$$

The value attached to a square meter of parks or public gardens decreases considerably when we increase the ray of the circle within we measure this amenity. This is confirmed by the figures presented in Table 3.3.

\begin{tabular}{|c|c|c|c|c|}
\hline \multirow[t]{2}{*}{ Table 3.3} & \multicolumn{4}{|c|}{ Mean marginal price for open space per $\mathrm{m}^{2}$ for different specifications of the variable } \\
\hline & $100 \mathrm{~m}$ circle & $300 \mathrm{~m}$ circle & $500 \mathrm{~m}$ circle & $1000 \mathrm{~m}$ circle \\
\hline (1) Amsterdam & 3.70 & 0.15 & 0.05 & 0.01 (ns) \\
\hline (1a) Amsterdam & 0.89 (ns) & 0.03 (ns) & 0.00 (ns) & $-0.01(\mathrm{~ns})$ \\
\hline Vondelpark & 10.73 & 0.51 & 0.22 & 0.06 \\
\hline (2) The Hague & 8.44 & 0.43 & 0.18 & 0.04 \\
\hline (3) Rotterdam & 6.78 & 0.32 & 0.13 & 0.05 \\
\hline
\end{tabular}

${ }^{13}$ The surface area of the corresponding circle is approximated by including the surface area of the grids of which the radius of the circle crosses. The differences between the surface area of a circle and the approximated surface area of a circle $e_{2}$ are however less than $2 \%$. 


\section{Demand for open space and land}

\subsection{Optimal provision of open space?}

Estimation of the hedonic price function allows us to verify the validity of condition (2.16). The willingness to pay for $1 \mathrm{~m}^{2}$ parks and public gardens within 500 meters of the house is equal to 0.05 euro for Amsterdam, 0.22 euro for The Hague and 0.18 euro for Rotterdam (see Table 3.3). To calculate the total willingness to pay for open space we have to sum the individual household's willingness to pay for open space over the total number of households living in the corresponding area. The total willingness to pay of open space, which is equal to the total benefits of open space, is calculated by the multiplication of the total number of households with the (individual) marginal price of open space. The number of households is positively related with the size of the area; the larger the circle, the larger the number of households will be. The number of households $(N)$ is calculated by the multiplication of the average number of households per hectare $(n)$ with the corresponding surface area per hectare $\left(=10000 \mathrm{~m}^{2}\right.$, approximately 2.5 acres). As shown in equation 3.1, in calculating the marginal price of open space per $\mathrm{m}^{2}$, we have to divide by the corresponding surface area. The total benefits of open space is therefore equal to:

$$
\begin{aligned}
T B_{\text {open space }} & =N * M P_{\text {open space }} \\
& =(n * \text { surfacearea }) *\left(\frac{\left.100 * \text { coefficient }_{\text {openspace }} * P\right)}{10000 * \text { surfacearea }}\right) \\
& =(n) *\left(\frac{\text { coefficient } \left._{\text {openspace }} * P\right)}{100}\right)
\end{aligned}
$$

with $n$ denoting the number of households per hectare, and $P$ the house price. As shown in equation 4.1 the size of the area cancels out in the calculation of the total willingness to pay for open space. The marginal prices of open space per $\mathrm{m}^{2}$ per hectare per household for the three cities are shown in Table 4.1, first column.

The results of the hedonic regression with respect to the willingness to pay of a household for an increase in $1 \mathrm{~m}^{2}$ floor area are presented in the second column of Table 4.1. The marginal price of floor area is very high in Amsterdam, which confirms the general impression that the pressure on the housing market is strong in Amsterdam. The high marginal price of floor area in Amsterdam also coincides with the fact that the average size of a house is smaller in Amsterdam than in The Hague and Rotterdam (see Table A. 2 in the appendix).

The implied price per hectare, which is the conventional unit for land transactions in the Netherlands, is high. According to Segeren (2007) the maximum price for residential land (ready for housing construction) is highest in the province of Utrecht, where it is still below 5 million euro per hectare. For North-Holland, where Amsterdam is located, 3.9 million is 
reported and for South-Holland, which includes Rotterdam and The Hague, 4.5 million. Even though it must be taken into account that these figures refer to whole provinces and not specifically to land in urban areas, it should also be noted that house prices are high throughout Utrecht, South Holland and the southern part of North Holland ${ }^{14}$ and that housing construction is concentrated on sites close to existing urban areas. Our estimation results suggest therefore that consumer's willingness to pay for private space is of the same order of magnitude as the market price for residential land.

\begin{tabular}{|c|c|c|c|c|}
\hline \multirow[t]{3}{*}{ Table 4.1} & \multicolumn{4}{|c|}{ Willingness to pay for open space and floor area } \\
\hline & $(1)^{a, b}$ & $(2)^{a}$ & (3) & (4) \\
\hline & $\begin{array}{r}\text { Marginal price open } \\
\text { space }\left(\mathrm{m}^{2} \text { per }\right. \\
\text { hectare, per } \\
\text { household })\end{array}$ & $\begin{array}{r}\text { Marginal price of floor } \\
\text { area }\left(\mathrm{m}^{2}, \text { per }\right. \\
\text { household })\end{array}$ & 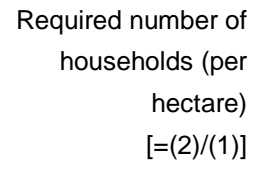 & $\begin{array}{r}\text { Actual number of } \\
\text { households (per } \\
\text { hectare) }\end{array}$ \\
\hline Amsterdam & $4.01(1.38)$ & $806(42)$ & 201 & 72 \\
\hline The Hague & $14.55(1.04)$ & $606(38)$ & 42 & 58 \\
\hline Rotterdam & $9.87(1.79)$ & $429(47)$ & 43 & 42 \\
\hline
\end{tabular}

By dividing the willingness to pay for private space by that for public space, we find the number of households per neighbourhood that is required to establish the equality in (2.16). The results of this computation are presented in column 3 and should be compared with the actual (average) number of households per hectare in the three cities, which is given in column (4).

The conclusions with respect to the optimal provision of open space are mixed. In Amsterdam the actual number of households is far lower than the number that is required to meet the cost-benefit rule. This suggests that these households would rather like to have more private space and less open space. In The Hague the actual number of households is higher than the required number, which suggests that the provision of open space is below its optimum level. In Rotterdam, the amount of open space is at its optimum ${ }^{15}$. As written in the previous section, our data suggest that open space still provides positive effects at distances larger than $500 \mathrm{~m}$. We find an increase in the total benefits of open space when the radial of the circle at which the effects of open space are measured, is enlarged to $1 \mathrm{~km}$, except for Amsterdam. Although the marginal benefits of open space derived by an individual household decreases

\footnotetext{
${ }^{14}$ The northern part of North Holland is mainly agricultural. Amsterdam is located in the southern part, which also includes towns like Haarlem, Hilversum and Hoofddorp (close to Amsterdam Schiphol airport) where house prices are also high. ${ }^{15}$ Because the coefficients of parks and public garden differ with respect to the specification of the range at which the amenity is calculated (Table 3.2), the total benefits of open space, and therefore the results whether the provision of open space is optimal or not, also differ between the alternative specifications. When the benefits of open space are calculated at 100 meter of the house, in all the three the cities the provision of open space is above its optimum level. However, when you consider the benefits of open space at $1 \mathrm{~km}$ circle around the house, the provision of open space is below its optimum in The Hague and Rotterdam.
} 
when we enlarge the circle (see Table 3.3), the total welfare effect is positive because the number of households increases.

We conclude with some caveats. An obvious and potentially important one is that our approach is only able to measure the value of open space that is reflected in house prices. This means that we can - at best - only measure the value that residents of the area attach to this amenity. The value that non-residents attach to the amenity may be as relevant, especially in areas that attract large numbers of tourists or where employees working close by go out for lunch. A second issue is that we could not take into account the deterioration of the quality of parks and public gardens that may be caused by the continual presence of people - for instance homeless people - who (correctly or not) give the impression to other visitors that the area is unsafe, not suitable for playing children, et cetera. These problems seem to be present in all large urban areas and can result in substantial changes in the value attached to public urban space (in extreme cases this value may even become negative).

\subsection{Demand for private and public space}

To get more insight into the factors that drive our results, we would like to know how the demand for parks and public gardens relates to income and whether private and public space are substitutes. Parks can perhaps be considered as the poor man's alternative for a private garden, and if true, this would suggest that demand for this amenity would decrease with higher incomes. On the other hand it may be argued that especially rich urban households, who live in apartments close to the city centre, will appreciate the presence of parks and public gardens and that this amenity is important for attracting such households to urban residential areas. The question whether and to what extent open space can be a substitute for private space is of obvious importance for both rich and poor households and has (at least potentially) implications for the design of cities.

Rosen's (1974) path breaking analysis of implicit markets proposed a two stage procedure that would provide answers to questions like these. The basic idea is that the combinations of the observed housing characteristic or amenity and its estimated marginal price can be interpreted as points on the demand curve for this characteristic of the households concerned. To find these demand curves, he suggested a second stage in the analysis. In this second stage of Rosen's procedure the marginal prices, which are estimated in the first stage, are regressed on the quantity of the characteristic using instrumental variables techniques.

After the publication of Rosen's two-stage procedure, it was pointed out that the identification problem associated with hedonic price analysis was more serious than was realized before. The problem is illustrated in Figure 4.1. Line A shows the relationship between 
the marginal price of a characteristic (e.g. open space) and the quantity consumed of that characteristic as implied by a hedonic price function. All combination of marginal price and quantity on the line refers to the optimum of a specific consumer and therefore to a point on the demand curve of that consumer. However, if all consumers are heterogeneous this is not helpful in identifying the slope of their demand curves. Such individual demand curves are drawn as dotted lines in the figure and it is clear that their slope cannot be inferred from the combination of marginal price and quantity implied by the estimated hedonic price function. Clearly, unobserved heterogeneity among households causes a serious identification problem for Rosen's second stage that has plagued the empirical implementation of the hedonic model. ${ }^{16}$

\section{Figure 4.1 Estimating demand for open space}

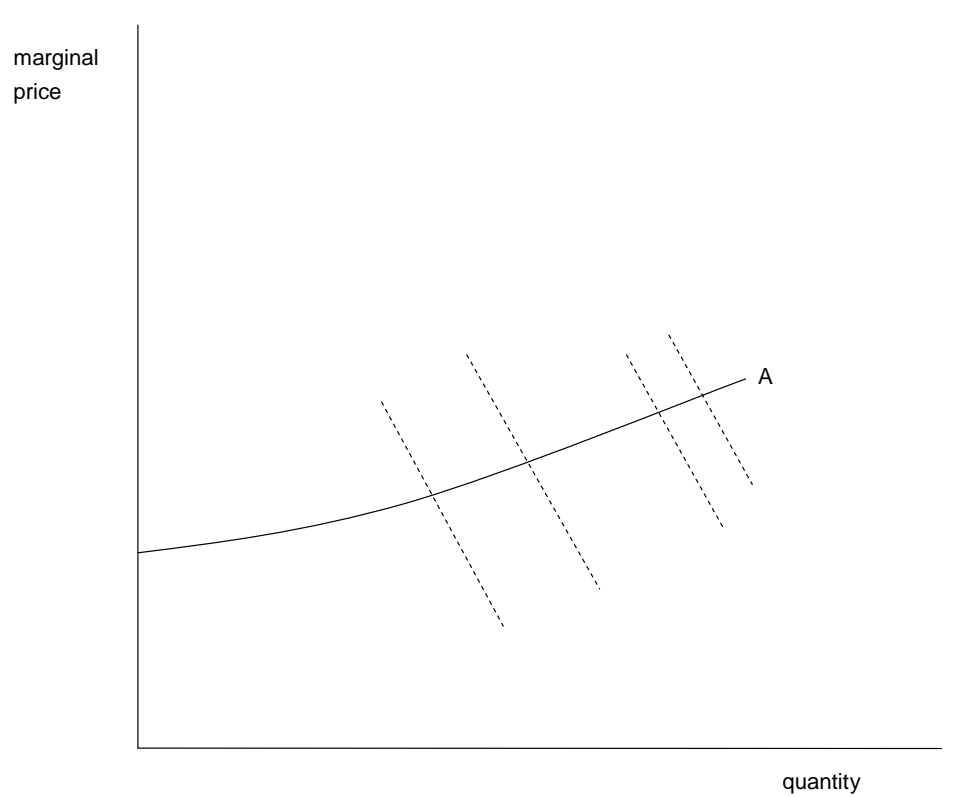

Recent analyses have attempted to avoid this problem by stressing that the information provided by the partial derivatives of the hedonic price functions is sufficient to recover the parameters of simple specifications of the utility function. ${ }^{17}$ However, this approach is less suitable for

\footnotetext{
${ }^{16}$ The identification problem was recognized by Bartik (1987) and Epple (1987) and the debate about its solution continues until the present day. See, for instance, Palmquist (2003) or section 3 of Ekeland, Heckman and Nesheim (2002) for recent discussions and proposed solutions.

${ }^{17}$ In particular, Bajari and Benkard (2005) argue that if the utility function for consumer $j$ is specified as: $u_{j}=c+\beta_{h j} \ln h+\beta_{S j} \ln S$, then the parameters can be recovered from the partial derivatives of the hedonic price function through the first-order condition: $\beta_{k j} / k_{j}=\partial P / \partial k_{j}, k=h, S$. The strength of this approach is that it takes full account of the heterogeneity among consumers. The price to be paid is that with cross section data one can only consider utility functions for which only one parameter of the utility function occurs in the marginal utility of each attribute. This is restrictive: the specified utility function is quasi linear, implying that the demand for each attribute does not depend on the consumer's income, and additive, implying that substitution between attributes is restricted. Because of the probable relationship between demand for open space and income and because we are interested in the extent to which open space can act as a
} 
investigating the effect of income on the demand for private and public space, and therefore we returned to earlier attempts to solve the identification problem through the use of instrumental variables. Many suggestions have been made in the literature, but most of them did not survive subsequent criticism (see, for instance, Palmquist, 2003, and Ekeland et al. 2002). One of the few remaining possibilities is identification by means of observations referring to multiple markets (see, for instance Kahn and Lang, 1988).

\section{Figure 4.2 Estimating demand for open space}

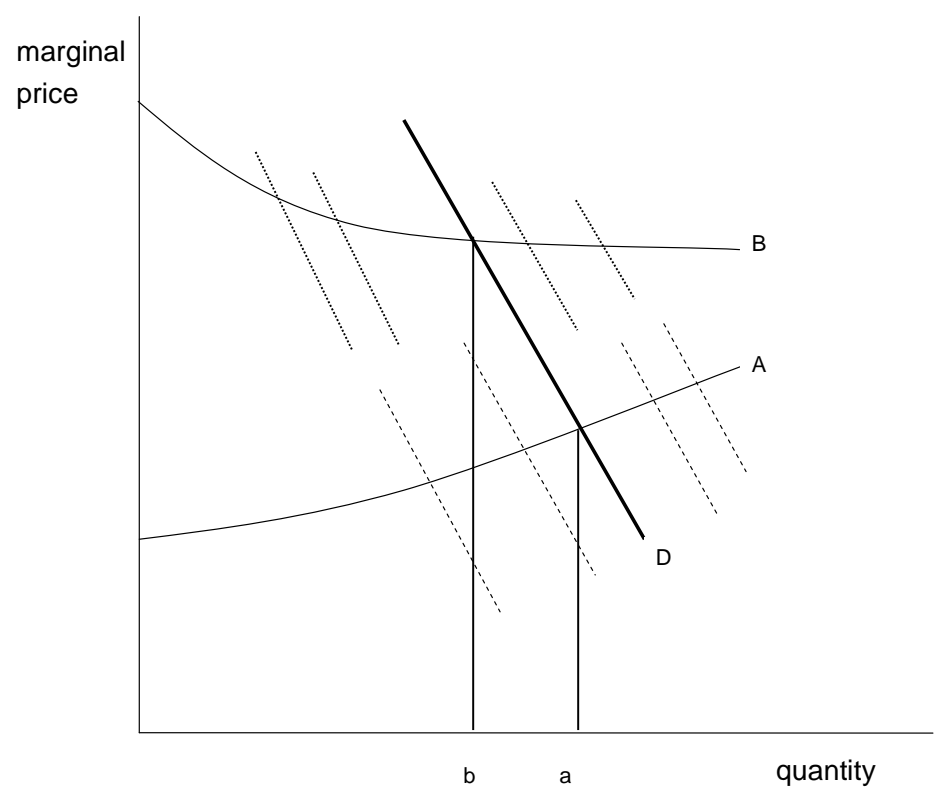

To see how this works, return to the utility maximization problem. The marginal willingness to pay for open space follows from the first order conditions. Assume that this marginal willingness to pay (or its logarithm) can be described by a linear inverse demand function with an intercept that is individual specific due to unobserved heterogeneity:

$\frac{\partial P}{\partial S}=a+\varepsilon-b S+c y$

where $\mathrm{a}, \mathrm{b}$ and $\mathrm{c}$ are coefficients and $\varepsilon$ is a random variable reflecting unobserved

heterogeneity. We assume that $\varepsilon$ has expectation 0 and is independent of income. Some examples of such linear demand curves are drawn as dashed lines in Figure 4.1. The hedonic price function implies that the marginal price of open space is a function of the amount of open space itself (as well as other housing characteristics, which we keep constant here). This gives a second equation:

substitute for private space, this approach is not appropriate for the research questions in which we are interested in this paper. 
$\frac{\partial P}{\partial S}=f(S)$

Individuals sort themselves on the housing market on the basis of their observed and unobserved characteristics and this introduces correlation between $\varepsilon$ and $\mathrm{S}$. Indeed, we can conclude from (4.2) and (4.3):

$\varepsilon=f(S)-a+b S-c y$.

This illustrates the difficulty of finding good instruments for $S$ in a regression equation based on (4.2). In such a regression $\varepsilon$ will be part of the residual and (4.4) shows that it will in general be correlated with $S$. However, if we have information about separate markets, we may take market dummies as instruments. The assumption that the populations in the various markets are identical, which means that they have the same parameters of their demand functions and the same distribution of the unobserved heterogeneity $\varepsilon$, allows us to estimate the parameters of the demand function, as is illustrated in Figure 4.2. In this figure a second relationship between marginal price and quantity of open space, referring to market B, has been added. In B the average marginal price of open space is higher than that in A, and the average quantity consumed is lower, and this allows us to estimate the slope of the individual inverse demand functions.

The basic assumptions of the approach we use are therefore that the parameters of individual inverse demand functions, including the distribution of the unobserved heterogeneity, are identical in both markets. Even though this implies that the structure of demand is similar in the two cities, the hedonic price functions, that represent market equilibria, may be different because of differences in the composition of the housing stock. Such differences may have been caused by the historical development of the cities. City dummies can therefore be used as instruments for the amount of open space. In Figure 4.2 the average quantities of open space for cities $A$ and $B$ are been indicated as $a$ and $b$, respectively. IV Regression on the pooled observations of both cities results in the line indicated as $D$ in the figure, which has indeed the slope of the demand curves of the individual households. The extension to the case of three (or more) markets and to other characteristics (like floor area) is obvious.

The above, somewhat informal, discussion makes clear that the IV approach that uses different geographical markets, assumes that the populations of consumers in the various cities are comparable. In this respect the fact that the three cities to which our empirical work refers are located in a small part of the Netherlands, which is a country with a relatively homogeneous population, is probably an advantage. The assumption of a similar structure of demand in these three cities is perhaps least appropriate for Amsterdam which is more cosmopolitan than the other two cities. In the previous section we noted that the historical development of the three cities - and their housing stock - was substantially different. 
The approach just discussed works also when the marginal price of open space depends on other housing characteristics as well. Moreover, more instruments can be found by using interactions of the city dummies and household characteristics, and we can investigate, for instance, the effects of income and family composition on the demand for open space. In our empirical work, reported in the next sections, we will use this approach.

\subsection{Estimation of the demand functions}

The database we used to estimate the hedonic price functions contains no information about buyers of the house. We have therefore combined the results of the estimated hedonic price functions with a different data base, the Housing Needs Survey (in Dutch: Woning Behoefte Onderzoek, usually abbreviated as WBO). This survey is held every four years and we used the 2002 version. Even though the survey contains a large number of observations (more than $60000)$, its national character and the low share of owner-occupation in the large Dutch cities, result in only a few hundred observations that can be used in each of these cities. The WBO data contain the self reported value of the house of the respondent, floor area, as well as the code area of the house. Our hedonic price function implies that the marginal price of an increase of one percent open space, is equal to the estimated coefficient for open space and the transaction price of the house; the marginal price of floor area equals the estimated coefficients for floor area, divided through the floor area, and multiplied by the house price. Since house price and floor area are included in the $\mathrm{WBO}$, we can use the results of the hedonic price equation (the coefficients for open space and floor area) if these two variables (house price and floor area) are equivalent in the NVM and WBO data.

Using this assumption we estimated demand equations for open space and floor area. We pooled the observations for the three cities. The total number of observations is 1671 , which is considerably smaller than the number of transactions we used for estimation of the hedonic price functions in either of the three cities. Besides income, we also include other households characteristics like the number of children, number of adults and age of the head of the household. ${ }^{18}$ We used the dummy variables Rotterdam and The Hague as instruments. The results with respect to the demand equations are shown in Table 4.2.

Column (1) and (2) show that both inverse demand functions are downward sloping, and that the slope is statistically significant, as is suggested by economic theory. Income has a significant positive effect on the demand for open space as well as on the demand for floor area. It shows that parks and public gardens is not an inferior good, and that the demand for open space for both rich citizens as for poor citizens is important. Current attempts to make Dutch cities more attractive to high income households should therefore not neglect the importance of

${ }^{18}$ Including these variables helps to avoid the potential problems associated with correlation between income and the unobserved heterogeneity among consumers. For instance, it is well known that households with children on average have a somewhat higher income than those without children.

22 
this amenity. The income elasticity of the demand for open space can be computed on the basis of the results presented in Table 4.2 and is equal to 0.25 . The income elasticity for floor area is computed similarly. It is somewhat higher and equals $0.34{ }^{19}$

The variables number of children, number of adults and the age of the head of the households also have significant positive coefficients. This means that an increase in the number of children (or an increase in the number of adults in the households), leads to an increase in the demand for open space and floor area. The older the age of the head of the household, the higher the demand for open space and floor area.

\begin{tabular}{|c|c|c|c|}
\hline & Log (marginal price open space) & Log (marginal price floo & \\
\hline & (1) & (2) & (3) \\
\hline Constant & $3.222(0.802)$ & $-0.015(0.746)$ & $-0.407(0.914)$ \\
\hline Log (income) & $0.344(0.080)$ & $0.699(0.080)$ & $0.737(0.097)$ \\
\hline Number children & $0.107(0.039)$ & $0.168(0.040)$ & $0.196(0.051)$ \\
\hline Number adults & $0.114(0.059)$ & $0.126(0.049)$ & $0.157(0.060)$ \\
\hline Age head household & $0.023(0.003)$ & $0.014(0.003)$ & $0.014(0.003)$ \\
\hline Percentage open space & $-0.154(0.023)$ & & $0.030(0.021)$ \\
\hline Floor area & & $-0.014(0.002)$ & $-0.016(0.011)$ \\
\hline N & 1671 & 1671 & 1671 \\
\hline Log likelihood & -2916 & -2204 & -2462 \\
\hline
\end{tabular}

The coefficient of the cross effect of open space on the inverse demand for floor area is insignificant, as reported in column (3). Our data therefore do not suggest that making more open space available in the city will significantly reduce the demand for private land.

\footnotetext{
${ }^{19}$ The income elasticity is calculated at the mean percentage of open space, which is equal to 8.85 percent, and at the mean of floor area, which is equal to $147 \mathrm{~m}^{2}$.
} 


\section{$5 \quad$ Summary and conclusions}

Dutch land use planning - and particularly its attempt to preserve open space outside cities has general support among the population. There is little doubt that this policy has contributed significantly to restricting urban sprawl in the central part of the Randstad (the so-called Green Heart), which is appreciated by many people. There has been less attention for the potentially disadvantageous side effects that come in the form of high building densities, high house prices and more pressure on open space within these borders. An investigation into the value attached by Dutch citizens to residential space and open space within cities seems therefore appropriate.

In this paper, we investigate some important welfare aspects of a specific spatial planning measure, the provision of open space within cities. We use the monocentric model of the city to derive a simple cost-benefit rule for the optimal provision of open space. This rule is essentially the Samuelson-condition for the optimal provision of a public good, with the price of land as the appropriate indicator for its cost. The condition has been made operational by computing the willingness to pay for public and private space on the basis of empirical hedonic price functions for three Dutch cities. In Amsterdam, The Hague and Rotterdam the presence of parks and public gardens within the vicinity of the house increases the value of the house. This means that households are willing to pay more for a house if the house is located in a neighbourhood with open space. Less surprising, but also important, is the fact that households are willing to pay more for a house if the floor area of the house is larger. Of the three investigated cities, the city of Amsterdam has the highest price per $\mathrm{m}^{2}$ floor area. This is in line with the tight housing market situation in Amsterdam and with the fact that the average floor area of the house is the smallest of the three cities. The willingness to pay for open space is lowest in Amsterdam. The quality of open space seems to have an influence on the willingness to pay.

The conclusions with respect to the optimal provision of open space in the three cities are mixed: in Amsterdam, this amenity appears to be oversupplied in the current situation. This confirms similar results obtained by Cheshire and Sheppard (2002) for the provision of accessible open space in an English situation. In The Hague, however, the amount of open space is below its optimum level, whereas in Rotterdam open space is at its optimum level. These results are conditional on the use of a 500 meter radius for the effect of open space, as is current practice in Dutch spatial planning.

Further investigation revealed that the willingness to pay for parks and public gardens increases with income, although not as fast as that for private residential space. 
Anas, A., Arnott, R., Small, K.A., 1998. Urban Spatial Structure, Journal of Economic Literature, 36, 1426-1464.

Anderson, A.T., West, S.E., 2006. Open space, residential property values, and spatial context, Regional Science and Urban Economics, 36, 773-789.

Bajari, P., Benkard, C.L., 2005. Demand Estimation with Heterogeneous Consumers and Unobserved Product Characteristics: A Hedonic Approach, Journal of Political Economy, 113, 1239-1276.

Bartik, T.J., 1987. The Estimation of Demand Parameters in Hedonic Price Models, The Journal of PoliticalEconomy, 95 (1), 81-88.

Bezemer, V., Visschedijk, P.A.M., 2003. Groene meters deel II: Analyse van het stedelijk groen in de G30 steden, Alterra, 833, Wageningen.

Brown, G. M., Pollakowski, H. O., 1977. Economic Valuation of Shoreline, Review of Economics and Statistics, 59(3), 272-278.

Cheshire, P., Sheppard, S., 1995. On the Price of Land and the Value of Amenities, Economica, $62,247-267$.

Cheshire, P., Sheppard, S., 1998. Estimating the demand for housing, land, and neighbourhood characteristics, Oxford Bulletin of Economics and Statistics, 60, 357-283.

Cheshire, P., Sheppard, S., 2002. Welfare Economics of Land Use Regulations, Journal of Urban Economics, 52, 2002, 242-269.

Deaton, A., Muellbauer, J., 1980. Economics and Consumer Behavior, Cambridge University Press, 1980.

Ekeland, I., Heckman, J. J., Nesheim, L., 2002. Identification and Estimation of Hedonic Models, cemmap working paper CWPO7/02.

Epple, D., 1987. Hedonic Prices and Implicit Markets: Estimating Demand and Supply Functions for Differentiated Products, Journal of Political Economy, 95, 59-80. 
Fischel, W., 1985. The Economics of Zoning Laws, Johns Hopkins University Press.

Fujita, M., 1989. Urban Economic Theory: Land Use and City Size, Cambridge University Press, Cambridge.

Geoghegan, J., 2002. The Value of Open Spaces in Residential Land Use, Land Use Policy, 19, 91-98.

Glaeser, E.L., Gyourko, J., 2003. The Impact of Zoning on Housing Affordability, NBER working paper 8835 .

Kelejian, H. H., Prucha, I.R., 1999. A generalized moments estimator for the autoregressive parameter in a spatial model, International Economic Review, 40, 509-533.

Kahn, S., Lang, K., 1988. Efficient Estimation of Structural Hedonic Systems, International Economic Review, 29, 157-166.

Luttik, J., 2000. The value of trees and open space as reflected by house prices in the Netherlands. Landscape and Urban Planning, 48, 161-167.

McConnell, V., Walls, M., 2005. The Value of Open Space: Evidence from Studies of Nonmarket Benefits. Resources for the Future Report.

Orford, S., 1999, Valuing the Built Environment, GIS and House Price Analysis, Ashgate.

Palmquist, R.B., 2003. Property Value Models, forthcoming in K.G. Mäler and J. Vincent (eds) Handbook of Environmental Economics, 2.

Quigley, J., Raphael, S., 2005. Regulation and the High Cost of Housing in California, American Economic Review, 95, P\&P.

Raad voor het Landelijk Gebied, 2005. Recht op groen: Advies over de groen kwaliteit van de openbare ruimte, Amersfoort.

Rietveld, P., Wagtendonk, A.J., 2004. The Location of New Residential Areas and the Preservation of Open Space: Experiences in the Netherlands. Environment and Planning A, 36, 2047-2063.

Rosen, S., 1974. Hedonic Prices and Implicit markets: Product Differentiation in Pure 26 
Competition. Journal of Political Economy, 82, 34-55.

Segeren, A., 2007. De grondmarkt voor woningbouwlocaties: Belangen en strategieën van grondeigenaren, Ruimtelijk Planbureau, NAi Uitgevers.

Sheppard, S., 1999. Hedonic Analysis of Housing Markets. In: E.S. Mills and P. Cheshire (eds.), Handbook of Regional and Urban Economics, Elsevier, pp. 1595-1635.

Small, K.A., Steimetz, S., 2007. Spatial Hedonics and the willingness to pay for residential amenities, Working Paper, 050631, University of California-Irvine.

VROM, LNV, VenW, EZ, 2006. Nota Ruimte: Ruimte voor Ontwikkeling, deel 4, tekst na parlementaire behandeling.

Visser, P., van Dam F., 2006. De prijs van de plek: Woonomgeving en woningprijs, Ruimtelijk Planbureau, NAi, Publishers. 


\section{Appendix}

\begin{tabular}{|c|c|c|}
\hline Table A.1 & names and definitions & \\
\hline Variable name & Definition & Unit \\
\hline Transaction price & Transaction price in the year 2000. & Euros \\
\hline Capacity & Volume of the house. & $\mathrm{m}^{3}$ \\
\hline Floor area & Size of the living area of the house. & $\mathrm{m}^{2}$ \\
\hline \multirow[t]{3}{*}{ Year of construction (8x) } & Dummy variables: equal one if the house is built before 1906 , or in the periods & \\
\hline & 1906-1930, 1931-1944, 1945-1959, 1960-1970, 1971-1980, 1981-1990. & \\
\hline & Reference are houses that are built after 1990. & 0,1 \\
\hline Gas heater & Dummy variable: equal one if the house has a gas heater. & 0,1 \\
\hline Garage & Dummy variable: equal one if the house has a garage. & 0,1 \\
\hline Garden & Dummy variable: equal one when the house have a garden. & 0,1 \\
\hline Number of rooms & Number of rooms of the house. & \\
\hline Terraced house & Dummy variable: equal one when the house is a terraced house. & 0,1 \\
\hline Free standing & Dummy variable: equal one when the house is free standing. & 0,1 \\
\hline Semi-detached & Dummy variable: equal one when the house is semi-detached. & 0,1 \\
\hline Apartment & Dummy variable: equal one when the house is an apartment. & 0,1 \\
\hline Monument house & Dummy variable: equal one if the house is a monument. & 0,1 \\
\hline Maintenance good & Dummy variable: quality of the inner part of the house is good. & 0,1 \\
\hline Maintenance bad & Dummy variable: quality of the inner part of the house is fair or bad. & 0,1 \\
\hline Distance & Distance to the city centre (central station). & $\mathrm{km}$ \\
\hline $\begin{array}{l}\text { Percentage ethnical } \\
\text { minorities }\end{array}$ & $\begin{array}{l}\text { Percentage of inhabitants of non-westerns origin in the vicinity of which the house } \\
\text { is located. }\end{array}$ & $\%$ \\
\hline Population density & Number of inhabitants per km². & \\
\hline Neighbourhood dummies & 14 in Amsterdam, 7 in The Hague, 9 in Rotterdam. & 0,1 \\
\hline Month dummies & Dummies of the month in which the house was sold. & 0,1 \\
\hline $\begin{array}{l}\text { Percentage parks and } \\
\text { public gardens }\end{array}$ & $\begin{array}{l}\text { Percentage of parks and public gardens, forest and water with a recreational } \\
\text { function within } 500 \text { meter from the house. }\end{array}$ & $\%$ \\
\hline $\begin{array}{l}\text { Percentage agricultural } \\
\text { land }\end{array}$ & Percentage of agricultural land within 500 meter from the house. & $\%$ \\
\hline $\begin{array}{l}\text { Percentage industrial } \\
\text { area }\end{array}$ & $\begin{array}{l}\text { Percentage of industrial area (building land and firm grounds) within } 500 \text { meter } \\
\text { from the house. }\end{array}$ & $\%$ \\
\hline Percentage service area & $\begin{array}{l}\text { Percentage of service area (shops and social and cultural activity) within } 500 \\
\text { meter from the house. }\end{array}$ & $\%$ \\
\hline Percentage open water & $\begin{array}{l}\text { Percentage of open water (IJ in Amsterdam, North-Sea in The Hague and the } \\
\text { river Maas in Rotterdam) within } 500 \text { meter from the house. }\end{array}$ & $\%$ \\
\hline
\end{tabular}




\begin{tabular}{|c|c|c|c|}
\hline \multirow[t]{2}{*}{ Table A.2 Descriptive: mean values } & & & \\
\hline & Amsterdam $(\mathrm{n}=3889)$ & The Hague $(n=4417)$ & Rotterdam $(n=2334)$ \\
\hline Transaction price & 238245.00 & 162616.23 & 162434.09 \\
\hline Capacity & 272.25 & 320.30 & 319.32 \\
\hline Floor area & 93.00 & 107.06 & 122.76 \\
\hline Build before 1906 & 0.18 & 0.07 & 0.04 \\
\hline Build in the period $1906-1930$ & 0.29 & 0.30 & 0.13 \\
\hline Build in the period $1931-1944$ & 0.09 & 0.27 & 0.24 \\
\hline Build in the period $1945-1959$ & 0.04 & 0.12 & 0.16 \\
\hline Build in the period $1960-1970$ & 0.12 & 0.09 & 0.12 \\
\hline Build in the period $1971-1980$ & 0.05 & 0.05 & 0.09 \\
\hline Build in the period $1981-1990$ & 0.09 & 0.03 & 0.11 \\
\hline Build after 1990 & 0.17 & 0.06 & 0.13 \\
\hline Gas heater & 0.16 & 0.20 & 0.13 \\
\hline Garage & 0.04 & 0.05 & 0.08 \\
\hline Garden & 0.26 & 0.33 & 0.39 \\
\hline Number of rooms & 3.33 & 4.36 & 3.89 \\
\hline Terraced house & 0.13 & 0.16 & 0.27 \\
\hline Detached & 0.01 & 0.00 & 0.01 \\
\hline Semi-detached & 0.01 & 0.01 & 0.03 \\
\hline Apartment & 0.85 & 0.83 & 0.69 \\
\hline Monument house & 0.03 & 0.01 & 0.00 \\
\hline Maintenance good & 0.90 & 0.83 & 0.87 \\
\hline Maintenance bad & 0.10 & 0.17 & 0.13 \\
\hline Distance to city centre $(\mathrm{km})$ & 4.03 & 3.53 & 3.72 \\
\hline Percentage ethnic minorities & 23.75 & 16.50 & 22.42 \\
\hline Population density per $\mathrm{km}^{2}$ & 12.19 & 10.99 & 8.05 \\
\hline Percentage parks and public gardens & 9.09 & 10.21 & 9.90 \\
\hline Percentage agricultural land & 1.55 & 1.35 & 3.77 \\
\hline Percentage industrial area & 5.55 & 3.57 & 6.00 \\
\hline Percentage service area & 5.18 & 6.05 & 8.58 \\
\hline Percentage open water & 8.96 & 2.95 & 7.63 \\
\hline
\end{tabular}

